\title{
Evidence Of Method Effects In Budget-Related Behavior Research
}

Alfred E. Seaman (E-mail: seamana@mcmaster.ca), McMaster University, Canada John J. Williams (E-mail: awilliams@ntu.edu.sg), Nanyang Technological University, Singapore

\begin{abstract}
Research has revealed numerous budget-related behavior (BRB) dimensions that describe managers' actions and interactions with their budgetary control systems. This research has been conducted using a survey questionnaire methodology. However, those responding to the questionnaires may do so on a basis other than the specific item content. This paper uses a structural equation approach to investigate systematic response bias in BRB survey type research. Data from Singaporean companies is used to test for the presence of response bias and results confirm this expectation. The implication is that future studies in this context should investigate the structure and potential impact of response bias.
\end{abstract}

\section{Introduction}

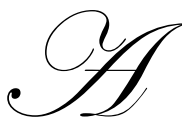

n organization's budgeting system is generally viewed as a system comprised of information flows, administrative processes and procedures that form an integral part of an organization's short-range planning and control system (Merchant, 1984; p83). Accounting research has largely focused on antecedents and consequences of individual budgeting system components. For example, the budget participation dimension has been used extensively in order to consider the impact of budget participation on performance (Flamholtz 1983; Milani, 1975; Kenis, 1979; Brownell, 1981, 1982, 1983; Chenhall and Morris, 1986; Govindarajan, 1986; Kren, 1992; Brownell and Dunk, 1991).

Research pertaining to the behavioral implications of budgeting at both the organization and the individual levels (Schiff and Lewin, 1968, 1970; Welsch, 1964; Wildavsky, 1963) has a lengthy history. Argyris' (1952) seminal work considered problems of human relations and budgeting while Hofstede (1967) considered the managerial motivation and control aspects of budgeting. Building on these foundation studies, DeCoster and Fertakis (1968), Swierenga and Moncur (1974), and Bruns and Waterhouse (1975) developed ten dimensions of budget-related behavior (called BRBs) that are related to budgeting activities and processes. These dimensions of behavior have subsequently been utilized in myriad combinations to examine the relationships among organization context, individual and organizational performance, and budgetary control systems (Bruns and Waterhouse, 1975; Merchant, 1981, 1984; Williams et al., 1990; Macintosh and Williams, 1992; Seaman et al., 2000; Seaman and Williams, 2001). This important and informative stream of research has been predominantly driven by a survey research methodology.

A potential outcome of survey type research methodology is response bias. Response bias is defined as the systematic tendency to respond to questionnaire items differently from what the latter were intended to measure (Paulhaus, 1991). Organizational behavior research has attempted to measure directly some of the variables associated with phenomena of response bias. For example, the bias may be associated with a temporary reaction to a situational demand (Paulhaus, 1991) or may be induced by contextual effects (Tourangeau and Rasinski, 1988). Response bias in a survey instrument may simultaneously provide an assessment of an individual's response style in addition to the variable of interest or context variable (Paulhaus, 1991). Thus, social desirability has been found to be correlated with a number of organizational research measures (Williams and Anderson, 1994). Moreover, it has

Readers with comments or questions are encouraged to contact the authors via email. 
been suggested that negative affectivity may be the cause of a number of observed relationships in studies dealing with job stress (Brief et al., 1988; Chen and Spector, 1991).

This paper uses a latent variable model approach and the LISREL program to determine whether response bias may be present in empirical BRB research. A better understanding of this bias contributes to the literature in the following important ways. First, this approach provides a direct test for the presence of response bias (i.e., method effects). Secondly, the detection of method effects provides a foundation for analyzing their effects on estimates of the substantive relationships under study. Thirdly, the specification of method effects (i.e., the nonsystematic variance) would permit an assessment of the impact from over/under estimating the structural coefficients.

\section{Background}

BRBs refer to the managerial activities, actions, and interactions that occur among managers regularly as a result of the operation of a budgetary control system (BCS) (Decoster and Fertakis,1968; Swierenga and Moncur, 1972, 1974; Bruns and Waterhouse, 1975; Williams et al., 1990; Macintosh and Williams, 1992). Dimensions of BRB have been identified with remarkable consistency in the research literature. Studies have developed and used a survey questionnaire to measure managers' BRBs, beginning with the work of Decoster and Fertakis (1968). Using exploratory factor analysis, a set of ten common BRBs has become dominant in the empirical literature. One recurring feature of the ten dimensions, the directly measured latent variables, is the consistency of their underlying component items. However, the issue of whether or not questionnaire responses demonstrate systematic tendencies that measure something other than the intended outcome has not been addressed in the empirical literature. Observing systematic bias in the data of the present study would offer evidence of a response bias.

Underlying the issue of response bias is the associated problem of construct measurement. Without adequate measurement, progress in any field is limited (Ganster et al., 1983). In management accounting research, questionnaires are a popular method of construct measurement for parsimonious reasons that include ease of use, low cost, and the general plausibility of measuring a variety of unobservable constructs. Respondents are queried about their attitudes, values, preferences, as well as their perceptions about organizational factors, work task characteristics, work group characteristics, role characteristics or the behaviors of other organizational participants (Ganster et al., 1983). Although it is the perceptions of the participants that are measured, the researcher is attempting to make inferences about the respondents' perceptions rather than about respondents' intrinsic values. Any questionnaire measure has factors that may operate to reduce their reliability and validity (Ganster et al., 1983). One important factor is response bias.

In organizational behavior research, attempts have been made to directly measure variables associated with response bias. Two variables used to measure response bias are Positive Affect (PA) and Negative Affect (NA). As explained by Watson et al. (1988) these two factors have consistently emerged in studies of affective structure. PA reflects the extent to which a person has feelings of being enthusiastic, alert and active. Low PA indicates sadness and lethargy while high energy, concentration and pleasurable engagement characterize high PA. However, NA indicates distress and unpleasurable engagement with low NA indicating a state of serenity and calmness. These particular conditions or states have been shown to systematically affect the manner in which subjects respond to survey questionnaires.

Ganster et al. (1983) developed conceptual and statistical models to test for the spuriousness and suppression effects resulting from response bias. They suggested that directly identifying bias would allow for testing its effects via a regression approach. Subsequently, Williams and Anderson (1994) developed a latent-variable modeling approach to investigate the spuriousness and suppression models developed by Ganster et al. (1983).

The brief overview of the BRB methodology, response bias, and the two affect constructs serves as a foundation for investigating potential response bias in the relevant BRB literature. It clearly suggests that the potential response bias effects are plausible and require further examination. Therefore, the purpose of this paper is to empirically test for the existence of response bias. Assuming that PA and NA are valid constructs that can uncover response bias, a model of response bias could be useful for several reasons. First, it would reveal whether response bi- 
as is potentially present in BRB research. Secondly, if it is shown to exist, then there is a need for future research to examine the impact. Thirdly, the relative impact of the response bias on the parameter estimates among the substantive constructs could be examined.

\section{Sample}

Companies from the Singapore directory of organizations were used in this study. The sample featured large decentralized organizations, spanning numerous operating units, which produced formal budgeting systems for departmental evaluation as part of their budget system design. Three criteria were employed for sub-unit selection. First, sub-unit heads had active responsibility in negotiating for budget resources. Secondly, the sub-unit size was between 20 and 80 full-time employees. Thirdly, managers of sub-units had at least one year of experience in dealing with their operating budgets. These criteria ensured a representative sample of multiple responses from knowledgeable individuals in each organization and knowledgeable responses on the behavioral dimensions of budgeting.

The sub-unit level was chosen because it has been bypassed in much of the BRB literature. Managers at this organization level are the lowest point of delegated budgetary responsibility. As a result of the selection criteria imposed, sub-units in this sample are relatively homogenous in operating terms. Hence, administrative and other non-operating sub-units were excluded from the sample.

For this study, 253 managers responded to a 44-item BRB questionnaire (Appendix A), which was chosen because of its acclaimed reliability and consensus on the ten BRB dimensions. A brief description of the BRB dimensions comprising the managerial budgeting activities is provided in Appendix B. It is responses on these activities that have provided researchers with the ability to gain insights into the complexity of the organizational budgeting environment. Managers also responded to the 20-item PANAS Scale (Appendix C) that was developed by Watson et al. (1988). Prior testing has confirmed the reliability, validity, and efficiency of the scale in measuring dimensions of mood.

\subsection{Measures}

The BRB dimensions were measured using the questionnaire developed by Decoster and Fertakis (1968) and modified by Swierenga and Moncur (1974), Bruns and Waterhouse (1975), Merchant $(1981,1984)$ and Williams et al. (1990, 1995). Department managers were asked to rate how often 44 budget-related activities occur on a scale from one (to a very little extent) to five (to a very great extent). Budgeting was defined as a planning and control exercise for the fiscal period dealing with the allocation and use of resources.

The PA and NA mood dimensions were measured using the PANAS Scales (Watson et al., 1988). Managers were asked to respond to the 20 descriptors of feeling by indicating to what extent they felt that way, on average. Responses were reported on a scale from one (very slightly or not at all) to five (extremely).

Table 1 shows the results of reliability analysis for the latent variables described above. Coefficient alpha values for the variables ranged from .55 to .87 , thus indicating acceptable reliability. Also included in Table 1 are the results of the factor analysis (FA) for each variable. All variables are uni-dimensional as shown by the eigenvalues and percentage of variance explained. However, BRB10 was dropped from the analysis as it did not attain appropriate reliability statistics.

Table 1

Reliability and Uni-dimensionality of Latent Variables

\begin{tabular}{|c|c|c|c|c|c|c|c|c|c|c|c|}
\hline & BRB1 & BRB2 & BRB3 & BRB4 & BRB5 & BRB6 & BRB7 & BRB8 & BRB9 & PA & NA \\
\hline Alpha & .73 & .81 & .68 & .77 & .64 & .72 & .83 & .66 & .55 & .87 & .86 \\
\hline $\begin{array}{l}\text { FA: } \\
\text { eigenvalue }\end{array}$ & $\begin{array}{l}1.95 \\
65 \%\end{array}$ & 1.68 & 1.50 & 2.04 & 1.47 & 1.59 & 2.23 & 1.49 & 1.34 & 3.92 & 3.77 \\
\hline
\end{tabular}


Figure 1

Latent Variable Model

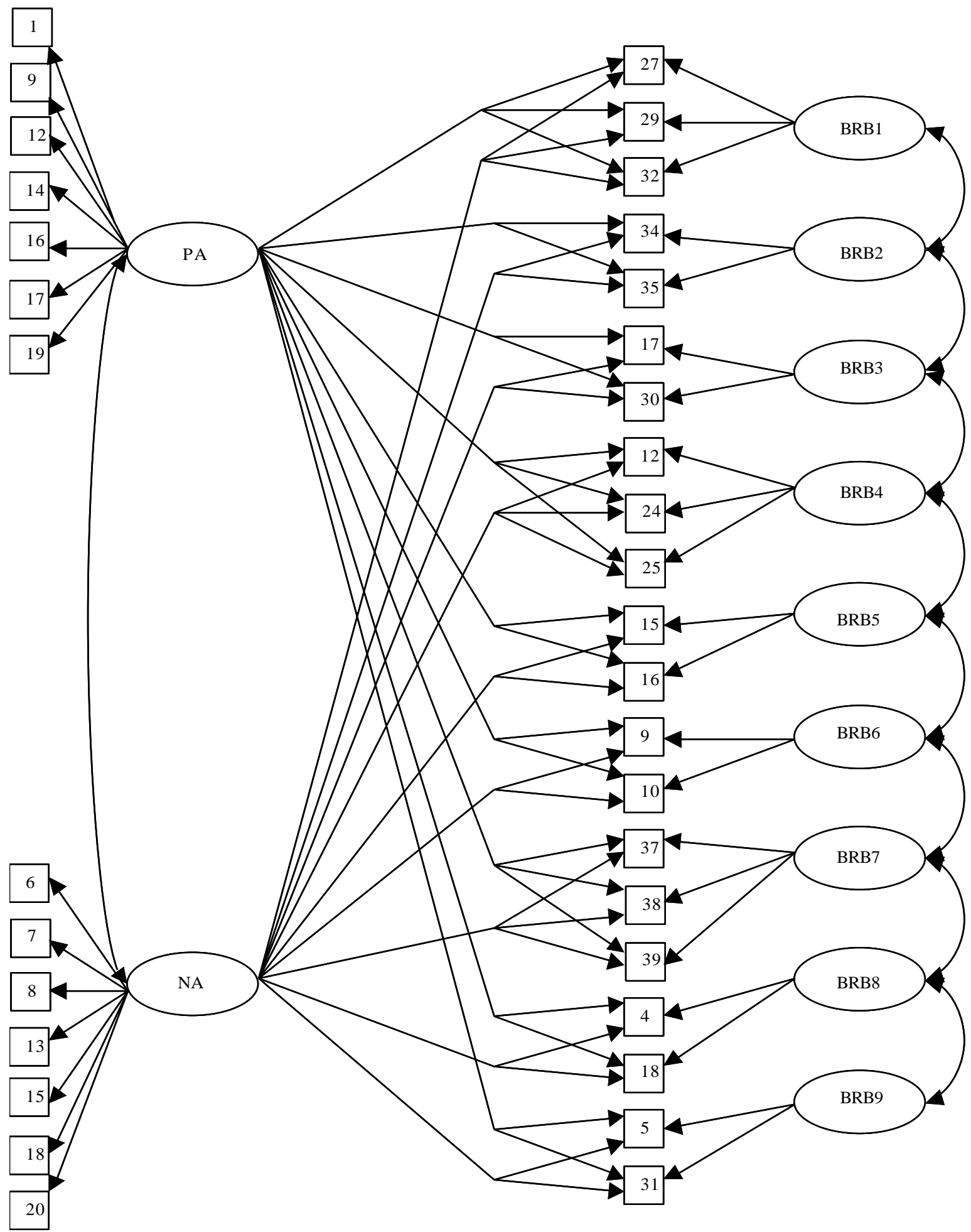




\subsection{Latent-Variable Model}

The model chosen for analysis consisted of nine BRB dimensions and the two PANAS Scales, NA and PA. Figure 1 is a representative multiple indicator model depicting relationships among the nine BRB dimensions. In the model, each of the 21 items chosen from the BRB questionnaire was allowed to load on only one BRB dimension. The dimension chosen for the items corresponds exactly to the BRB dimensions utilized in previous studies thus providing a detailed and identified initial model for confirmatory factor analysis (CFA) (Bollen, 1989). All item errors are assumed to be uncorrelated with the BRBs being allowed to correlate freely.

The variables measuring bias are then incorporated into the model. The two constructs are measured using seven items from ten available for each construct. Three indicators measuring the PA and NA constructs were dropped from the analysis, as they did not provide appropriate factor loadings. The two constructs are allowed to correlate with each other freely but are shown as not being related to any of the BRB dimensions through factor correlations or structural parameters. However, PA and NA are expected to influence the indicators of the nine BRB dimensions.

\subsection{Analysis of Data}

The data was subjected to CFA using the LISREL(Version 8.51) program (Joreskog and Sorbom, 1993) and adopting the methodology developed by Williams and Anderson (1994). Un-weighted Least Squares was chosen as the method of parameter estimation based on the fact that the data set exhibited violations of the normality assumption. The saturated model with method effects is shown in Figure 1. In this model, the impact of the response bias latent variables was allowed to be different for each of the indicators of the BRB dimensions. This allows the test for response bias to be conducted without making any assumptions about the nature of the bias. A second model was evaluated to determine the overall significance of the response bias. The second model was derived by constraining to zero the 42 paths from the BRB dimension indicators to the PA and NA bias constructs representing the effects of PA and NA on the BRB dimension indicators. This resulted in a structural model without response bias effects.

These two versions of the model, one containing response bias effects and the other with no response bias effects were compared using a chi-square difference test. This comparison tested the hypothesis that there were no response bias effects due to the presence of PA and NA in this data set.

\section{Results and Discussion}

The results of the latent variable model analysis are displayed in Table 2. These results yield a significant chi-square difference: $\Delta X^{2}{ }_{(\mathrm{df}=42)}=94.01, \mathrm{p}<.001$ indicating support for the rejection of restricting the response bias effects to zero. This suggests that response bias factor loadings should be retained. In addition to the chi-square difference test, the CFI provided in Table 2 shows the role of the measurement and substantive effects within both models. The CFI for Model 2 is .96 indicating that the largest part of the variance and covariance is accounted for by the measurement model without response bias effects. Model 1 shows a slight improvement in fit, CFI=. 99, with the PA and NA factor loadings affecting the substantive indicators.

Table 2

Results For The Latent Variable Models Examined

\begin{tabular}{|l|c|c|c|}
\hline \multicolumn{1}{|c|}{ Model } & $\boldsymbol{X}^{\mathbf{2}}$ & $\boldsymbol{d} \boldsymbol{f}$ & CFI* $^{*}$ \\
\hline 1. Saturated structural model with method effects & 1169.35 & 478 & .99 \\
\hline 2. Saturated structural model without method effects & 1263.36 & 520 & .96 \\
\hline
\end{tabular}

*CFI = Comparative Fit Index

These results demonstrate that response bias was present in the current research. This paper does not attempt to determine the specific nature of the effects such as the relative impact of PA or NA on the individual substantive indicators or their impact on relationships among the substantive variables. However, we do show that both PA and NA have impacts on the BRB indicators. Eleven of the twenty-one indicators have significant loadings for 
PA while eight loadings to NA are significant. The notion that response bias is present may potentially provide insight into inconsistencies in some of the previous BRB research findings.

\section{Summary and Limitations}

This paper has presented a latent variable model to demonstrate the presence of response bias. Given this finding, it is possible that response bias exists in all the survey research reported in the management accounting literature. However, more effort is required to determine the contribution of both the PA and NA bias constructs and their relative impact on the BRB variables. Specifically, further analyses of the PA and NA bias effects could help to determine if it is necessary to expend the extra effort and resources to discover the specification bias effects.

Limitations of the latent-variable approach need to be highlighted. First, even though PA and NA response bias were controlled, other sources of method variance were not (Williams and Anderson, 1994). Secondly, the latent-variable model that contains response bias effect factor loadings is very highly parameterized. In addition to the parameters estimated for the BRB constructs, 42 response bias parameters were estimated above the number required for the model without response bias effects. This raises concerns over capitalizing on chance or model overfitting from a complex model (Williams and Anderson, 1994). Thirdly, although the latent-variable model produces the most desirable parameter estimates, it cannot resolve the issues associated with substantive constructs that are not included in the model (Williams and Anderson, 1994). Fourthly, there is a concern that the inclusion of bias variables may have a substantial affect on the minimum sample size required for reliable structural equation estimation due to the loading of each substantive indicator on each bias variable (Williams and Anderson, 1994). Clearly, an increase in the number of measurement parameters increases the required sample size.

In the present study, all of the BRB variables were allowed to correlate with each other thereby producing a saturated model. This approach is not unusual with BRB systems since they are components of a larger budgetary control system (Seaman and Williams, 2001). Importantly, a saturated model does not bias the test for the response bias as undertaken by comparing Model 1 and Model 2. Thus, in studies using subsets of the BRBs, such as budget participation and its components, it may be of interest to consider whether or not response bias may have contributed to the mixed results achieved in prior studies.

Other limitations of this research study are also recognized. When using cross-sectional data, path analysis models do not permit causality statements (Bollen, 1989; Williams and Liu, 1995). When a path model fits the data, our assumptions are not contradicted and they should be considered valid because there may be other models and assumptions that fit the data (Bollen, 1989). Because sub-units within the organizations included in our sample were not randomly selected, this may have contributed some bias. These and other possible limitations do not diminish the fact that response bias is present in this data. Further research is needed to determine the effects of response bias in the complex behavioral budgeting environment both within and among organizations.

\section{References}

1. Agyris, C. 1952. The Impact of Budgets on People. Ithaca: The Controllership Foundation, Inc., Cornell University.

2. $\quad$ Bollen, K.A. 1989. Structural Equations with Latent Variables. New York,NY:John Wiley \& Sons.

3. Brief, A.P., Burke, M.J., George, J.M., Robinson, B.S., and J. Webster. 1988. Should Negative Affectivity Remain an Unmeasured Variable in the Study of Job Stress? Journal of Applied Psychology, 73: 193-198.

4. Brownell, P. 1981. Participation in Budgeting, Locus of Control and Organizational Effectiveness. The Accounting Review: $844-850$.

5. Brownell, P. 1982. The Role of Accounting Data in Performance Evaluation, Budgetary Participation, and Organizational Effectiveness. Journal of Accounting Research 35: 12-27.

6. Brownell, P. 1983. Leadership Style, Budgetary Participation and Managerial Behaviour. Accounting, Organizations and Society: 307-321.

7. Brownell, P. and A. S. Dunk. 1991. Task Uncertainty and Its Interaction with Budgetary Participation and Budgetary Emphasis: Some Methodological Issues and Empirical Investigation. Accounting, Organizations and Society 16 (8): 693-703.

8. Bruns, W.J. and J.H. Waterhouse. 1975. Budgetary Control and Organizational Structure. Journal of Account- 
ing Research (Autumn): 177-203.

9. Chen, P and P. Spector. 1991. Negative Affectivity as the Underlying Cause of Correlations Between Stressors and Strains. Journal of Applied Psychology, 76: 398-407.

10. Chenall, R. H. and Morris D. 1986. The Impact of Structure, Environment and Interdependence on the Perceived Usefulness of Management Accounting Systems. The Accounting Review: 16-25.

11. DeCoster, D. and J.P. Fertakis.1968. Budget-Induced Pressure and Its Relationship to Supervisory Behaviour. Journal of Accounting Research (Autumn): 237-246.

12. Flamholtz, E. G. 1983. Accounting, Budgeting and Control Systems in their Organizational Context: Theoretical and Empirical Perspectives. Accounting, Organizations and Society: Vol.8,No.2/3: 153-169.

13. Ganster, D.C., Hennessey, H.W., and F. Luthans. 1983. The Social Desirability Response Effects: Three Alternative Models. Academy of Management Journal: Vol. 26, No. 2: 321-331.

14. Govindarajan, V. 1986. Decentralization, Strategy, and Effectiveness of Strategic Business Units in Multibusiness Organizations. Academy of Management Review: 844-856.

15. Hofstede, G. H. 1967. The Game of Budget Control. Netherlands, Koninklijke Van Grocum.

16. Joreskog, K.G. and D. Sorbom. 1993. LISREL8: Structural Equation Modelling with the SIMPLIS Command Language. Chigago, IL: Scientific Software.

17. Kenis, L. 1979. Effects of Budgetary Goal Characteristics on Managerial Attitudes and Performance. The Accounting Review:707-721.

18. Kren, L. 1992. Budgetary Participation and Managerial Performance: The Impact of Information and Environmental Volatility. The Accounting Review 67: 511-526.

19. Macintosh, N. B. and J. J. Williams. 1992. Managerial Roles and Budgeting. Behavioral Research in Accounting: 23-48.

20. Merchant, K.A. 1981. The Design of the Corporate Budgeting System: Influences on Managerial Behaviour and Performance. The Accounting Review (October): 813-829.

21. Merchant, K.A. 1984. Influences on Departmental Budgeting: An Empirical Examination of a Contingency Model. Accounting, Organizations and Society 9 (3/4): 291-307.

22. Milani, K. 1975. The Relationship of Participation in Budget Setting to Industrial Supervisor Performance and Attitudes: A Field Study. The Accounting Review (April): 272-284.

23. Paulhus, D. 1991. Measurement and Control of Response Biases. In J.P. Robinson, P.R. Shaver, \& L. Wrightsman(Eds.). Measures of Social Psychological Attitudes. San Diego, CA: Academic Press.

24. Schiff, M., and A. Y. Lewin. 1968. Where Traditional Budgeting Fails. Financial Executive: 57-63.

25. Schiff, M., and A. Y. Lewin. 1970. The Impact of People on Budgets. The Accounting Review: 259-268.

26. Seaman, A.E, Landry, R., and J.J. Williams. 2000. Budget-Related Behavior: Resolving A Portion Of The Performance Puzzle In The Management Accounting System. The Review Of Accounting Information Systems, Volume 4, Number 1: 51-68.

27. Seaman, A. E. and J.J. Williams. 2001. Evidence Of a Second-order Factor In A System Of Budget-Related Behavior Dimensions. The International Applied Business Research Conference, Conference Proceedings, Cancun, Mexico, March, 2001.

28. Swieringa, R. J. and R. H. Moncur. 1972. The Relationship between Managers' Budget-Oriented and Selected Attitude, Position, Size, and Performance Measures. Empirical Research in Accounting: Selected Studies, Supplement to Journal of Accounting Research: 194-209.

29. Swieringa, R.J. and R.H. Moncur. 1974. Some Effects of Participative Behaviour on Managerial Behaviour. New York, NY: National Association of Accountants.

30. Tourangeau, R. and K.A. Rasinski. 1988. Cognitive Processes Underlying Context Effects in Attitude Measurement. Psychological Bulletin, 103: 299-314.

31. Watson, D., Clark, L.A. and A. Tellgen. 1988. Development and Validation of Brief measures of Positive and Negative Affect: The PANAS Scales. Journal of Personality and Social Psychology. Vol. 54, No. 6: 10631070.

32. Welsch, G. A. !964. Budget Profit Planning and Control. Second Edition. Englewood Cliffs: Prentice Hall.

33. Wildavsky, A. 1963. Politics of the Budgetary Process. Boston:Little, Brown.

34. Williams, L.J. and S.E. Anderson. 1994. An Alternative Approach to Method Effects by Using Latent-variable Models: Applications in Organizational Behavior Research. Journal of Applied Psychology. Vol.79, No. 3: 323-331. 
35. Williams, J.J. and M.H. Liu. 1995. Budget Participation and Satisfaction: The Influence of Managerial Interactions and Task Uncertainty. Accounting and Business Review 2 (1): 85-110.

36. Williams, J.J., N.B. Macintosh, and J.C. Moore. 1990. Budget Related Behaviour in Public Sector Organizations: Some Empirical Evidence. Accounting, Organizations and Society 15 (3): 221-246.

\section{Appendix A \\ Budget-Related Behavior Questionnaire}

1. $\quad$ Normally I start preparing the budget for my department (unit) before I am asked to.

2. I spend time outside of normal working hours preparing the budget for my unit.

3. I am not able to spend as much time as I would like preparing the budget for my unit.

4. I work with my superior in preparing the budget for my unit.

5. I work with my subordinates in preparing the budget for my unit.

6. I work with other unit heads in preparing the budget for my unit.

7. I work with financial staff people in preparing the budget for my unit.

8. I am consulted about special factors I would like to have included in the budget being prepared.

9. New budgets include changes I have suggested.

10. The budget is not finalized until I am satisfied with it.

11. Preparing the budget for my unit requires my attention to a great number of details.

12. I am reminded of the importance of meeting the budget for my unit.

13. I am evaluated on my ability to meet the budget for my unit.

14. I have difficulty meeting the budget for my unit.

15. I am shown comparisons of actual and budgeted performance for other units.

16. My explanation of budget variances is included in performance reports.

17. I investigate favourable as well as unfavourable budget variances for my unit.

18. I go to my superior for advice on how to achieve my budget.

19. I am required to prepare reports comparing actual results with budget.

20. My methods of reaching budgeted performance are accepted without question by my superior.

21. My methods of reaching budgeted performance are accepted without question by my subordinates.

22. My superior calls me in to discuss variations from the budget.

23. My superior accepts my explanation of budget variations in my unit.

24. My superior expresses dissatisfaction to me about results in my unit when the budget has not been met.

25. My superior mentions budgets when talking to me about my efficiency as a manager.

26. I ask for assistance from staff departments concerned with budgeting.

27. I am required to submit an explanation in writing about causes of large budget variances.

28. I use the budget to plan activities in my unit.

29. I am required to trace the cause of budget variances to groups or individuals within my unit.

30. I personally investigate budget variances in my unit.

31. I evaluate my subordinates by means of the budget.

32. I am required to report actions I take to correct causes of budget variances.

33. I find it necessary to stop some activities in my unit when budgeted funds are used up.

34. I find it necessary to charge some activities to other accounts when budgeted funds for these activities have been used up.

35. I have to shift figures relating to operations to reduce budget variances.

36. Budget matters are mentioned in informal conversations.

37. I express my opinions on budget matters.

38. I offer suggestions for the improvement of budget systems.

39. The budgeting system is changed in accordance with my suggestions.

40. I discuss budget items when problems occur.

41. The budget enables me to be more flexible.

42. The budget enables me to be more innovative.

43. The budget enables me to keep track of my success as a manager.

44. The budget enables me to be a better manager. 
Appendix B.

Description Of The Ten BRB Dimensions

Dimension 1: Required Variance Explanation is defined as the extent to which the manager is required to report and explain variances, identify causes and report corrective actions.

Dimension 2: Budget Reaction is defined as the extent to which managers stop activities or charge activities to other accounts or shift figures to other accounts to reduce variances.

Dimension 3: Budget Analysis is defined as the extent to which managers attend to detail in budget preparation, investigate all budget variances within their unit of responsibility.

Dimension 4: Evaluation By budget is defined as the extent to which superiors evaluate the manager using the budget to assess efficiency and express dissatisfaction about results.

Dimension 5: Participation in Feedback is defined as the extent to which managers are shown performance reports of other units and have explanations included in performance reports and have budget matters mentioned to them.

Dimension 6: Budget Influence is defined as the extent to which managers' changes are included in budgets and budgets are not finalized until they are satisfied.

Dimension 7: Budget Involvement is defined as the extent to which managers express opinions, offer suggestions and has the budget changed in accordance with these suggestions.

Dimension 8: Interaction With Superiors is defined as the extent to which managers seek advice from or work with superiors in preparing the budget.

Dimension 9: Interaction With Subordinates is defined as the extent to which managers discuss budget items, evaluate, and work with subordinates in preparing budgets.

Dimension 10: Enabling Change is defined as the extent to which the budget enables the manager to be more innovative and flexible.

$\begin{array}{ll}\begin{array}{l}\text { Appendix C. } \\ \text { Affectivity Quesstion }\end{array} \\ \text { 1. } & \text { Interested } \\ 2 . & \text { Distressed } \\ \text { 3. } & \text { Excited } \\ \text { 4. } & \text { Upset } \\ \text { 5. } & \text { Strong } \\ 6 . & \text { Guilty } \\ 7 . & \text { Scared } \\ \text { 8. } & \text { Hostile } \\ 9 . & \text { Enthusiastic } \\ \text { 10. } & \text { Proud } \\ \text { 11. } & \text { Irritable } \\ \text { 12. } & \text { Alert } \\ \text { 13. } & \text { Ashamed } \\ \text { 14. } & \text { Inspired } \\ \text { 15. } & \text { Nervous } \\ \text { 16. } & \text { Determined } \\ \text { 17. } & \text { Attentive } \\ \text { 18. } & \text { Jittery } \\ \text { 19. } & \text { Active } \\ \text { 20. } & \text { Afraid } \\ \end{array}$


Notes 